\title{
Retracted: Structural, electrical, and optical properties of ATO thin films fabricated by dip coating method
}

\author{
Talaat M Hammad ${ }^{1 *}$ and Naser K Hejazy ${ }^{2}$
}

\begin{abstract}
Retraction
This article was mistakenly published twice. For this reason this duplicate article has now been retracted. For citation purposes please cite the original: http://www.inljournal.com/?_action=articlelnfo\&article=22

Abstract

Antimony-doped tin oxide (ATO) thin films were prepared by dip coating method. The effect of antimony doping on the structural, electrical, and optical properties of tin oxide thin films were investigated. Tin(II) chloride dehydrate $\left(\mathrm{SnCl}_{2} \cdot 4 \mathrm{H}_{2} \mathrm{O}\right)$ and antimony $(\mathrm{III})$ chloride $\left(\mathrm{SbCl}_{3}\right)$ were used as a host and a dopant precursor, respectively. X-ray diffraction analysis showed that the non-doped $\mathrm{SnO}_{2}$ thin film had a preferred (211) orientation, but as the Sb doping concentration increased, a preferred (200) orientation was observed. The lowest resistivity (about $5.4 \times 10^{-3} \Omega \mathrm{cm}$ ) was obtained for Sb-doped films at 2 at.\%. Antimony doping led to an increase in the carrier concentration and a decrease in Hall mobility. The transmittance of ATO films was observed to increase to $96 \%$ at 2 at.\% Sb doping, and then, it was decreased for a higher level of antimony doping.
\end{abstract}

Keywords: Electrical properties, Optical properties, ATO, Thin films, Dip coating

\section{Background}

Transparent conducting oxide (TCO) films are widely used in a variety of optoelectronic devices such as solar cells, displays, and electrochromic devices. In recent years, there has been a growing interest in the application of TCO films as electrodes in solar cell devices. Among the TCO films, the most appropriate material for the application seems to be tin oxide films, which are chemically inert, mechanically hard, and heat resistant. In addition, they exhibit low electrical resistivity and high optical transmittance. Either doped or non-doped, tin oxide thin films can be fabricated by a number of techniques: chemical vapor deposition [1], sputtering [2], sol-gel coating [3], and spray pyrolysis [4-6]. The sol-gel method has such advantages as cheap cost and flexible deposition technique. Such properties can be improved by doping tin oxide with, for example, antimony (Sb), indium (In), or fluorine $(\mathrm{F})$. In fact, by increasing the doping concentration

\footnotetext{
* Correspondence: talaath55@yahoo.com

'Physics Department, Faculty of Science, Al-Azhar University, P.O. Box 1277, Gaza Strip, Gaza, 00970, Palestine

Full list of author information is available at the end of the article
}

$(>2 \%)$, a degenerate semiconductor is formed, displaying higher $\sigma$ values $\left(>103 \Omega^{-1} \mathrm{~cm}^{-1}\right)$. Since this doping level is not too high, doped $\mathrm{SnO}_{2}$ thin films are transparent for visible light, which makes them useful for a device application point of view. Also, the nature, quantity, and structural distribution of doping are important factors for the electrical properties of $\mathrm{SnO}_{2}$ [7].

The current study investigates the characteristics of Sb-doped $\mathrm{SnO}_{2}$ thin films prepared by dip coating technique. The structural, electrical, and optical properties of the thin films are examined in relation to the increase in the antimony amount.

\section{Methods}

The antimony-doped tin dioxide sols were prepared using the same methodology utilized in our previous literature [8]. The $\mathrm{SnO}_{2}$ solution was obtained by dissolving $2.01 \mathrm{~g}$ of $\mathrm{SnCl}_{4} \cdot 4 \mathrm{H}_{2} \mathrm{O}$ in $25 \mathrm{ml}$ of absolute ethanol. To achieve $\mathrm{Sb}$ doping, antimony trichloride $\left(\mathrm{SbCl}_{3}\right)$ was added to the precursor solution. The amount of $\mathrm{SbCl}_{3}$ to be added depends on the desired doping concentration. The doping concentration varied from 0 to 7 at.\%. The solution was 
stirred at $70^{\circ} \mathrm{C}$ for $6 \mathrm{~h}$ in a closed container for the homogenous mixing of the solution and then was aged in the air for $24 \mathrm{~h}$, i.e., until the solid materials dissolved. The thin films were deposited by dip coating technique on glass substrates, which had been cleaned ultrasonically in acetone, rinsed in DI water, and then dried by $\mathrm{N}_{2}$ blowing. The clean glass substrates were dipped vertically and carefully into the sol, left for a short time, and withdrawn from the bath at withdrawal speeds in the range of 1 to $10 \mathrm{~mm} / \mathrm{s}$. This was followed by drying and then sintering of the films between $400^{\circ} \mathrm{C}$ and $550^{\circ} \mathrm{C}$ for periods ranging from 6 to $24 \mathrm{~h}$. To obtain higher thickness films, the sequence of dipping, drying, and then dipping again was performed a number of times. However, sintering was done only after the final dipping. The thickness of the films increased almost linearly with the number of times of dipping. The films were kept at $25^{\circ} \mathrm{C}$ and humidity of $40 \% \mathrm{RH}$. All measurements were performed in the same conditions and after the final annealing. The film thickness, $t$, was measured with a Tencor P10 profilometer, (KLA-Tencor Corporation, Milpitas, CA, USA). The measurement accuracy of this equipment for the thickness measurement is $0.1 \mathrm{~nm}$. The sheet resistance, $R$, of the films was measured by the linear four-point method. The electrical resistivity, $\rho$, was determined by the relation $\rho=R t$. The optical transmittance of the films was measured using a UV-visible spectrophotometer (Cary 500, Agilent Technologies, Inc., Santa Clara, CA, USA). Crystal structure identification and crystal size analysis were carried out by Xray diffraction (XRD) (2000, SCintag Inc., Cupertino, $\mathrm{CA}, \mathrm{USA}$ ) with a $\mathrm{Cu}-\mathrm{K} \alpha$ radiation source and a scan rate of $2^{\circ} / \mathrm{min}$.

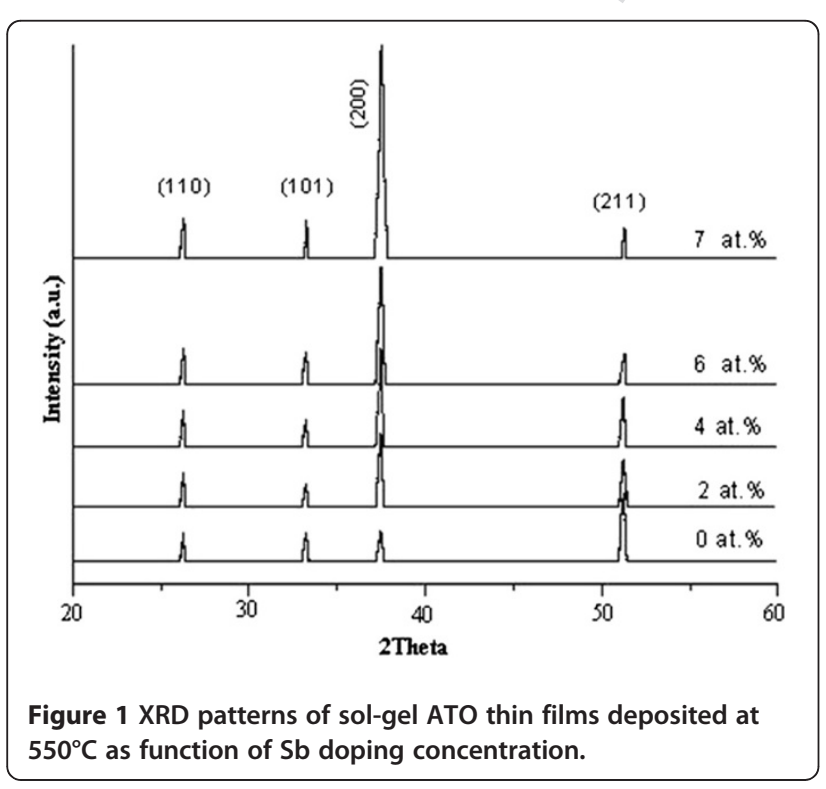

\section{Results and discussion}

Figure 1 shows the XRD patterns of the sol-gel ATO thin films with a $220-\mathrm{nm}$ thickness deposited at $550^{\circ} \mathrm{C}$ as a function of $\mathrm{Sb}$ doping concentration. The preferred orientation changed with $\mathrm{Sb}$ doping. The non-doped $\mathrm{SnO}_{2}$ thin films had a preferred (211) orientation. However, as the $\mathrm{Sb}$ doping amount increased, the intensity of the (211) peak decreased and the (200) peak intensity increased.

Thus, the preferred (200) orientation was observed for Sb-doped films at 2 to 7 at.\%. The preferred (200) orientation was also reported by Elangovan et al. [6]. This behavior with $\mathrm{Sb}$ doping implies that in the present case, antimony incorporation in $\mathrm{SnO}_{2}$ lattice has not affected the structural properties to a considerable extent. On the other hand, for higher dopant levels, the incorporation would take place at interstitial sites, and some precipitation like antimony oxides $\left(\mathrm{Sb}_{2} \mathrm{O}_{3}, \mathrm{Sb}_{2} \mathrm{O}_{4}\right.$, and $\left.\mathrm{Sb}_{2} \mathrm{O}_{5}\right)$ could be induced [9]. As a result, with the increase of doping concentration, the deposited films lose the crystallinity, and the preferred orientation growth of $\mathrm{SnO}_{2}$ films may be suppressed by the precipitation. In the present case, antimony incorporation in $\mathrm{SnO}_{2}$ lattice has not affected the structural properties to a considerable extent. It is also clear that in Figure 1, the crystallinity improves initially with antimony doping up to 7 at.\% in the present case, but it decreases progressively beyond 7 at \% doping concentration, as observed by Shanthi et al. [10].

The effect of doping on the electrical properties of ATO thin films has been investigated. Figure 2 shows the variation of the resistivity $(\rho)$ with different $\mathrm{Sb}$ doping concentration (atomic percentage). The resistivity of ATO thin films decreases initially with an increase in the $\mathrm{Sb}$

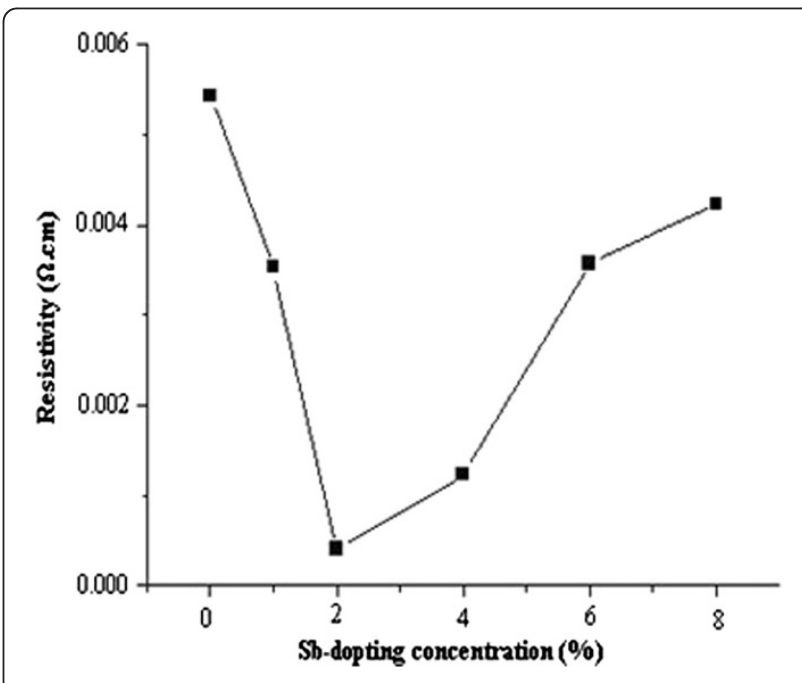

Figure 2 Resistivity of ATO thin films with Sb doping concentration. 
doping concentration to about $4 \times 10^{-4} \Omega \mathrm{cm}$ for 2 at.\% of $\mathrm{Sb}$ but increases again for further doping. The observed minimum is significantly less than that for pure $\mathrm{SnO}_{2}$ thin films $\left(5.4 \times 10^{-3} \Omega \mathrm{cm}\right)$. The decrease in resistivity which may be attributed to the substitution of $\mathrm{Sn}^{4+}$ by $\mathrm{Sb}^{5+}$ [10], as their ionic radii match $\left(\mathrm{Sn}^{4+} 0.071 \mathrm{~nm}\right.$ and $\mathrm{Sb}^{5+}$ $0.065 \mathrm{~nm}$ ). The variation in the resistivity of tin oxide thin films with antimony doping is explained on the basis of the presence of $\mathrm{Sb}$ in two oxidations states, namely $\mathrm{Sb}^{5+}$ and $\mathrm{Sb}^{3+}$. The possible mechanism may be as follows. When $\mathrm{SnO}_{2}$ is doped with $\mathrm{Sb}$, a part of the lattice $\mathrm{Sn}^{4+}$ atoms are replaced by $\mathrm{Sb}^{5+}$, resulting in the generation of conduction electrons and thus the decrease of resistivity $[11,12]$. Hence, a continuous decrease of resistivity is observed until $\mathrm{Sb}$ doping concentration $\leq 2$ at.\%. Beyond 2 at.\% of $\mathrm{Sb}$, the resistivity increases again (Figure 2). This is because beyond 2 at.\% of $\mathrm{Sb}$ doping, a part of $\mathrm{Sb}^{5+}$ ions reduces to the $\mathrm{Sb}^{3+}$ state, resulting in the formation of acceptor sites and concomitant loss carriers [13-16]. The reduction of $\mathrm{Sb}^{5+}$ to $\mathrm{Sb}^{3+}$ has been verified by Terrier et al. [12] by estimation of the lattice parameter of the doped $\mathrm{SnO}_{2}$ films. Since the ionic radius of $\mathrm{Sn}^{4+}$ is less than that of $\mathrm{Sn}^{3+}$ but higher than that of $\mathrm{Sn}^{5+}$, an increase in the lattice parameter of $\mathrm{SnO}_{2}$ phase is observed beyond 2 at.\% of $\mathrm{Sb}$ doping. This reduction of $\mathrm{Sb}^{5+}$ to $\mathrm{Sb}^{3+}$ can be attributed to the increase in the resistivity above an optimum level of $\mathrm{Sb}$ doping.

It is observed that this substitution increases the carrier concentration and thereby decreases resistivity. Thus, we could obtain the thin films which have the lowest resistivity at 2 at.\% $\mathrm{Sb}$ doping level. The resistivity $\rho$ is proportional to the reciprocal of the product of carrier

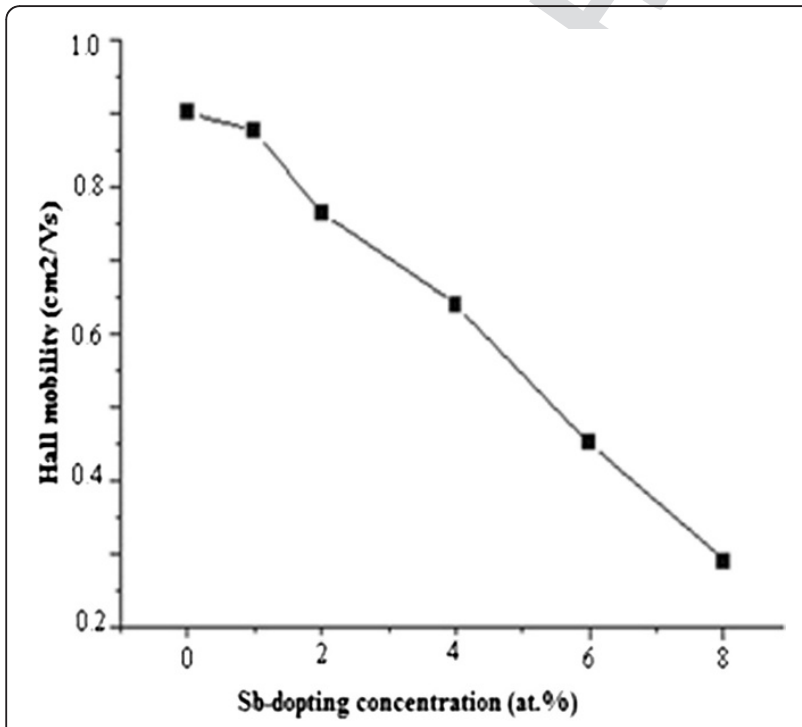

Figure 3 Hall mobility of ATO thin films as a function of Sb doping concentration.

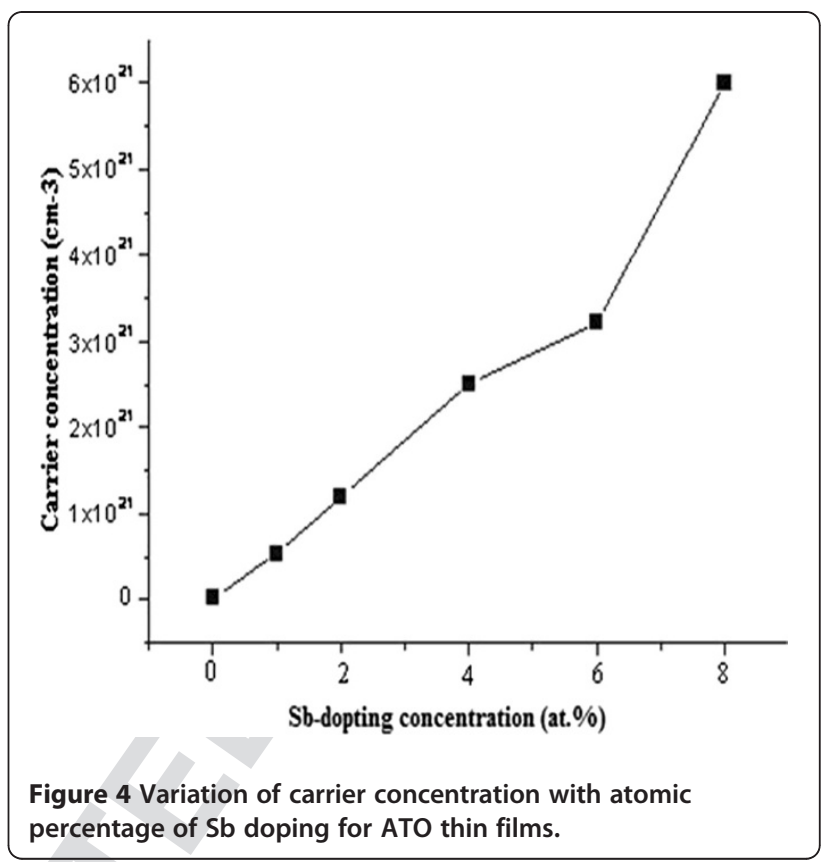

concentration $n$ and Hall mobility $\mu$, as in the following equation:

$$
\rho=\frac{1}{n e \mu} .
$$

As shown in Figure 3, Hall mobility decreased from 0.9024 to $0.2901 \mathrm{~cm}^{2} / \mathrm{Vs}$ with $\mathrm{Sb}$ doping. The increase in Hall mobility may be attributed to the (1) increase in the addition of antimony at the tin site and (2) a decrease in grain boundary scattering. It is known that grain boundary scattering and ionized impurity scattering are two major scattering mechanisms determining the mobility

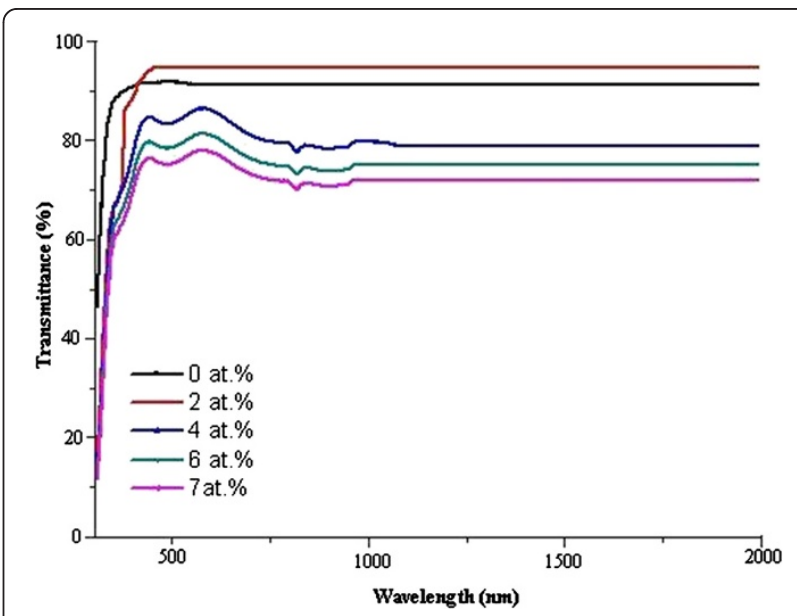

Figure 5 Optical transmissions of undoped $\mathrm{SnO}_{2}$ and several $\mathrm{Sb}$-doped $\mathrm{SnO}_{2}$ thin films as a wavelength function. 
variation of such extrinsic doped semiconductors. The resultant mobility is given as follows:

$$
1 / \mu=1 / \mu_{\mathrm{gb}}+1 / \mu_{\mathrm{is}}
$$

where $\mu$ is the resultant mobility; $\mu_{\mathrm{gb}}$ is the mobility due to grain boundary scattering; and $\mu_{\text {is }}$ is the mobility due to ionized impurity scattering. These observations are in close coincidence with those of Shanthi [10], Agashe [17], and Advani [18]. Figure 4 shows the carrier concentration of thin films with an increase in $\mathrm{Sb}$ doping concentration. The substitution of $\mathrm{Sn}^{4+}$ by $\mathrm{Sn}^{5+}$ led to an increase in the carrier concentration because the radii of the two ions matched. The carrier concentration of $\mathrm{SnO}_{2}$ thin films was $2.004 \times 10^{19} \mathrm{~cm}^{-3}$ and the value increased continuously with $\mathrm{Sb}$ doping to $6 \times 10^{19} \mathrm{~cm}^{-3}$ at 8 at.\% $\mathrm{Sb}$ doping concentration. The effect of doping on the optical properties of ATO thin films has been investigated. Figure 5 shows the transmittance spectra of ATO thin films with a thickness of $220 \mathrm{~nm}$ in the range of 300 to 2,000 nm. Maximum transmittance is found to be $96 \%$ (at $502 \mathrm{~nm}$ ) for the ATO film doped with 2 at.\% of $\mathrm{Sb}$, which is attributed to the low scattering effect and thickness uniformity of the film due to surface smoothness of the film. However, the transmittance is found to decrease gradually if the antimony concentration is increased above 2 at.\%. The decrease in transmittance with the increase in dopant concentration may be attributed to the increase in cluster size and surface roughness of the film, which promotes the diffuse and multiple reflections at the surface and increases the absorption. These observations are well in agreement with the results illustrated by Advani et al. and Manifacier [18,19], Jarzebski [20], Ambrazeviciene [21], and Shanthi [22]. In the case of heavily doped semiconductors with carrier concentration being approximately $10^{19}$ to $10^{21} \mathrm{~cm}^{-3}$, the Drude model can be generally used to represent the decrease in the transmittance [23-25]. Briefly, the model indicates that the transmittance drop in the near infrared region is associated with the plasma frequency $\left(\omega_{\mathrm{p}}\right)$ that can be expressed as follows:

$$
\omega_{\mathrm{p}}=\left[\frac{n e^{2}}{\varepsilon_{\mathrm{o}} \varepsilon_{\infty} m^{*}}\right]^{1 / 2},
$$

where $n$ is the carrier concentration; $e$, the electronic charge; $\varepsilon_{0}$, the permittivity of free space; $\varepsilon_{\infty}$, the high-frequency permittivity; $m^{*}$, the conductivity effective mass. Below the plasma frequency, the films are characterized by a high reflectance, which functions as a screen of the incident electromagnetic wave [25]. As $\omega_{\mathrm{p}}$ is proportional to the square root of the carrier concentration, the increase in the carrier concentration led to the lowering of the transmittance level near the infrared region.

\section{Conclusions}

Transparent conducting ATO thin films were prepared by dip coating method via sol-gel route. A preferred (211) orientation was observed for the non-doped $\mathrm{SnO}_{2}$ thin films, but as the $\mathrm{Sb}$ doping concentration increased, a preferred (200) orientation appeared for Sb-doped films at 3 to 7 at.\%. With the increase in the Sb doping concentration, the polyhedron-like grains became rounder and smaller. The carrier concentration of $\mathrm{SnO}_{2}$ thin films was $2.004 \times 10^{19} \mathrm{~cm}^{-3}$, and the value increased continuously with $\mathrm{Sb}$ doping to $6 \times 10^{19} \mathrm{~cm}^{-3}$ at 8 at.\% $\mathrm{Sb}$ doping concentration, while the Hall mobility decreased from 0.9024 to $0.2901 \mathrm{~cm}^{2} /$ Vs. The resistivity decreased to 2 at.\% Sb doping concentration; thereafter, it increased. Thus, the lowest resistivity (about $5.4 \times 10^{-3}$ $\Omega \mathrm{cm}$ ) was obtained for the Sb-doped films at 2 at.\%. The most effective transparent conducting ATO thin film was the Sb-doped films at 2 at.\%.

\section{Competing interests}

The authors declare that they have no competing interests.

\section{Authors' contributions}

$\mathrm{NKH}$ made the experiment on the thin films and performed tests on the samples. TMH carried out the characterization and wrote the manuscript. $\mathrm{TMH}$ gave the final approval of the version to be published. All the authors read and approved the final manuscript.

\section{Authors' information}

TMH is a professor of Material Science in the Physics Department, Faculty of Science in Al-Azhar University, Gaza, Palestine. He got his Ph.D. (May 1998) in Solid State Physics from Moscow State University. His research interests include solid state physics, thin film coating, material science, and nanotechnology (nanoparticles, nanowires, nanorods). NKH is an assistant professor of Physical Chemistry in the Chemistry Department in Al-Quds Open University, Gaza, Palestine. He got his Ph.D. (February 2009) in Physical Chemistry from Ain Shames University, Cairo, Egypt. His main research areas are thin film coating and nanostructure and their characterizations.

\section{Acknowledgments}

The authors would like to gratefully appreciate the financial support from the DAAD and Saarland University, Germany. We also acknowledge the editor who made the significant revision and contribution towards our article.

\section{Author details}

'Physics Department, Faculty of Science, Al-Azhar University, P.O. Box 1277, Gaza Strip, Gaza, 00970, Palestine. ²Department of Education, Al-Quds Open University, Gaza Branch, Gaza Strip, Gaza, 00970, Palestine.

Received: 23 February 2011 Accepted: 10 February 2012

Published: 19 June 2012

\section{References}

1. Fang, T.H., Chang, W.J.: Effect of freon flow rate on tin oxide thin films deposited by chemical vapor deposition. Appl Surf Sci 220, 175 (2003). doi:10.1016/S0169-4332(03)00817-1

2. Ma, J., Hao, X., Huang, S., Huang, J., Yang, Y., Ma, H.: Comparison of the electrical and optical properties for $\mathrm{SnO}_{2}: \mathrm{Sb}$ films deposited on polyimide and glass substrates. Appl Surf Sci 214, 208-213 (2003). doi:10.1016/S0169-4332(03) 00344-1

3. Lee, S.C., Lee, J.H., Oh, T.S., Kim, Y.H.: Fabrication of tin oxide film by sol-gel method for photovoltaic solar cell system. Sol Energy Mater Sol Cells 75, 481-487 (2003). doi:10.1016/S0927-0248(02)00201-5

4. Fukano, T., Motohiro, T.: Low-temperature growth of highly crystallized transparent conductive fluorine-doped tin oxide films by intermittent spray 
5. Thangaraju, B:: Structural and electrical studies on highly conducting spray deposited fluorine and antimony doped $\mathrm{SnO}_{2}$ thin films from $\mathrm{SnCl}_{2}$ precursor. Thin Solid Films 402, 71-78 (2002)

6. Elangovan, E., Ramesh, K., Ramamurthi, K.: Studies on the structural and electrical properties of spray deposited $\mathrm{SnO}_{2}: \mathrm{Sb}$ thin films as a function of substrate temperature. Solid State Commun 130, 523-527 (2004). doi:10.1016/j.ssc.2004.03.015

7. Mishra, K.C., Johnson, K.H., Schmidt, P.C: Electronic structure of antimony-doped tin oxide. Phys Rev B: Condens Matter 51, 13972-13976 (1995)

8. Hammad, T.M., Tamous, H.M., Hejazy, N.K.: Effect of argon plasma treatment on the electrical and optical properties of sol gel antimony-doped tin dioxide thin films fabricated by dip coating. Int J Mod Phys B 21, 4399 (2007)

9. Kim, K.H., Lee, S.W., Shin, D.W., Park, C.G.: Effect of antimony addition on electrical and optical properties of tin oxide film. J Am Ceram Soc 77, 915-921 (1994)

10. Shanthi, S., Subramanian, C., Ramasamy, P.: Growth and characterization of antimony doped tin oxide thin films. J Cryst Growth 197, 858 (1999)

11. Grosse, P., Schmitte, F.J.: Preparation and growth of $\mathrm{SnO}_{2}$ thin films and their optical and electrical properties. Thin Solid Films 90, 309-315 (1982). doi:10.1016/0040-6090(82)90382-0

12. Terrier, C., Chatelon, J.P., Berjoan, R., Roge, J.A.: Sb-doped $\mathrm{SnO}_{2}$ transparent conducting oxide from the sol-gel dip-coating technique. Thin Solid Films 263, 37-41 (1995). doi:10.1016/0040-6090(95)06543-1

13. Kaneko, H., Miyake, K: Physical properties of antimony-doped tin oxide thick films. J Appl Phys 53, 3629-3634 (1982). doi:10.1063/1.331144

14. Mulla, I.S., Soni, H.S., Rao, V.J., Sinha, A.P.B.: Deposition of improved optically selective conductive tin oxide films by spray pyrolysis. J Mater Sci 21, 1280-1288 (1986)

15. Nakanishi, Y., Suzuki, Y., Nakamura, T., Hatanaka, T., Fukuda, Y., Fujisawa, A., Shimoka, G.: Coloration of Sn-Sb-O thin films. Appl Surf Sci 48-49, 55 (1991). doi:10.1016/0169-4332(91)90307-6

16. Kojima, M., Kato, H., Gatto, M.: Optical and electrical properties of amorphous Sb-Sn-O thin films. Philos Mag B 73, 289 (1996). doi:10.1080/ 01418639609365824

17. Agashe, C., Takwale, M.G., Marathe, B.R., Bhide, V.G.: Structural properties of SnO2: F films deposited by spray pyrolysis technique. Thin Solid Films 17, 99-117 (1988). doi:10.1016/0165-1633(88)90010-X

18. Advani, G.N., Jordan, A.G., Lupis, C.H.P., Longini, R.L.: A thermodynamic analysis of the deposition of $\mathrm{SnO}_{2}$ thin films from the vapor phase. Thin Solid Films 62, 361-368 (1979). doi:10.1016/0040-6090(79)90012-9

19. Manifacier, J.C.: Thin metallic oxides as transparent conductors. Thin Solid Films 90, 297-308 (1982). doi:10.1016/0040-6090(82)90381-9

20. Jarzebski, Z.M., Marton, J.P.: Physical properties of $\mathrm{SnO}_{2}$ materials. J Electrochem Soc 123(333C), 199C-205C (1976). doi:10.1149/1.2133010

21. Ambrazeviciene, V., Galdikas, A., Grebinskij, S., Mironas, A., Tvardauskas, H.: Gas-sensing properties of chemically deposited SnOx films doped with Pt and Sb. Sens. Actuators B 17, 27-33 (1993)

22. Shanthi, S., Subramanian, C., Ramasamy, P: Investigations on the optical properties of undoped, fluorine doped and antimony doped tin oxide films. Cryst Res Technol 34, 1037 (1999). doi:10.1002/(SICl)1521-4079(199909)34:8

23. Hamberg, I., Granqvist, C.G.: Evaporated $\mathrm{Sn}$-doped $\mathrm{In}_{2} \mathrm{O}_{3}$ films: basic optical properties and applications to energy-efficient windows. J Appl Phys 60, R123 (1986). doi:10.1063/1.337534

24. Marcel, C., Naghavi, N., Couturier, G., Salardenne, J., Tarascon, J.M.: Scattering mechanisms and electronic behavior in transparent conducting $\mathrm{Zn}_{x} \mid \mathrm{n}_{2} \mathrm{O}_{x+3}$ indium-zinc oxide thin films. J Appl Phys 91, 4291 (2002). doi:10.1063/ 1.1445496

25. Coutts, T.J., Young, D.L., Li, X.: Characterization of transparent conducting oxides. MRS Bull 25, 58 (2000). doi:10.1557/mrs2000.152

doi:10.1186/2228-5326-2-7

Cite this article as: Hammad and Hejazy: Retracted: Structural, electrical, and optical properties of ATO thin films fabricated by dip coating method. International Nano Letters 2012 2:7.

\section{Submit your manuscript to a SpringerOpen ${ }^{\circ}$ journal and benefit from:}

- Convenient online submission

- Rigorous peer review

- Immediate publication on acceptance

- Open access: articles freely available online

- High visibility within the field

- Retaining the copyright to your article

Submit your next manuscript at $>$ springeropen.com 